\title{
SINONASAL ANATOMICAL VARIATIONS IN PATIENTS WITH CHRONIC RHINOSINUSITIS
}

\author{
Sabreena Hamza Nadwi', Manoj Gopalan², Sindhu V. Nath³, Satheesh Somaraj4
}

1 Postgraduate Resident, Department of ENT, Government Medical College, Trivandrum, Kerala, India. ${ }^{2}$ Associate Professor (CAP), Department of ENT, Government Medical College, Trivandrum, Kerala, India. ${ }_{3}$ Associate Professor (CAP), Department of ENT, Government Medical College, Trivandrum, Kerala, India. 4 Professor and HOD, Department of ENT, Government Medical College, Trivandrum, Kerala, India.

\section{ABSTRACT}

\section{BACKGROUND}

The anatomy of nose and paranasal sinuses is complex, and many anatomical variations have been described in these areas, which have been implicated in the occurrence and severity of rhinosinusitis. The aim of this study is to determine the sinonasal anatomical variations and their prevalence in patients with chronic rhinosinusitis, who are planned and worked up for endoscopic sinus surgery, with the help of computed tomography.

\section{MATERIALS AND METHODS}

A total of 86 patients with chronic rhinosinusitis, undergoing endoscopic sinus surgery in the Department of ENT, Medical College, Thiruvananthapuram, were studied with the help of computed tomography and the sinonasal anatomical variations were recorded and analysed. Sample size was taken for convenience.

\section{RESULTS}

Out of the 86 patients studied, $83.7 \%$ of patients had at least one sinonasal anatomical variation. Of the variations studied, deviated nasal septum (DNS) was the most common (73.25\%), followed by concha bullosa (37.2\%). 81.4\% of the patients had bilateral chronic rhinosinusitis (CRS) while $18.6 \%$ had unilateral disease. All the patients with unilateral CRS had single or multiple anatomical variations affecting the same side.

\section{CONCLUSION}

All the patients with unilateral disease had single or multiple anatomical variations affecting the same side which suggests the role of anatomical variations in the aetiology of chronic rhinosinusitis.

\section{KEY WORDS}

Chronic Rhinosinusitis, Sinonasal Anatomical Variations, Endoscopic Sinus Surgery, Computed Tomography

HOW TO CITE THIS ARTICLE: Nadwi SH, Gopalan M, Nath SV, et al. Sinonasal anatomical variations in patients with chronic rhinosinusitis. J. Evolution Med. Dent. Sci. 2019;8(11):769-773, DOI: 10.14260/jemds/2019/169

\section{BACKGROUND}

Rhinosinusitis is a common disease for which a person seeks medical care in the department of ENT. Chronic rhinosinusitis (CRS) is defined as a group of disorders characterized by inflammation of the mucosa of the nose \& paranasal sinuses for at least 12 consecutive weeks duration. ${ }^{1}$ The clinical diagnosis of rhinosinusitis is based on a group of symptoms classified as major and minor symptoms (Lanza \& Kennedy criteria). It requires two major or one major \& two minor factors to make a clinical diagnosis of rhinosinusitis. ${ }^{1}$

Chronic rhinosinusitis (CRS) sometimes doesn't get cured by medical line of management, necessitating surgical intervention. The main aim of functional endoscopic sinus surgery is the removal of disease in the ostiomeatal complex region, thereby restoring the normal mucociliary drainage of the sinuses.

'Financial or Other Competing Interest': None.

Submission 14-01-2019, Peer Review 02-03-2019,

Acceptance 08-03-2019, Published 18-03-2019.

Corresponding Author:

Dr. Manoj Gopalan,

Sreelakam, SNRRA-133,

Sreenarayana Guru Road,

Ulloor Medical College P. O.

Trivandrum-695011,

Kerala, India.

E-mail: manoj.g.ent@gmail.com

DOI: $10.14260 /$ jemds/2019/169
The complexities of the anatomy of nose \& paranasal sinuses as well as its anatomical variations may create technical difficulties during surgery. The significance of these anatomical variations in the pathogenesis of rhinosinusitis is still unclear. Theoretically, these variations could shift \& compress the ostiomeatal complex components, preventing mucus drainage $\&$ thus predispose to chronic rhinosinusitis.

\section{Aim \\ To study the sinonasal anatomical variations and their prevalence in patients with chronic rhinosinusitis with the help of computerized tomography.}

\section{MATERIALS AND METHODS}

A total of 86 patients with chronic rhinosinusitis, undergoing endoscopic sinus surgery in the Department of ENT, Medical College, Thiruvananthapuram, were studied with the help of computed tomography and the sinonasal anatomical variations were recorded and analysed. Sample size was taken for convenience.

\section{Inclusion Criteria}

Patients attending the Department of ENT, Govt. medical college, Thiruvananthapuram with a clinical diagnosis of chronic rhinosinusitis who were planned and worked up for endoscopic sinus surgery were included in the study. 


\section{Exclusion Criteria}

Patients with history of previous sinus surgery, facial trauma or benign or malignant tumours of sinonasal mucosa, and patients with any condition causing immunosuppression were excluded.

The nasal anatomy varies significantly among individuals, and the significance of an anatomical variation is determined by its relationship to the ostiomeatal unit and nasal air passages. The ability of the variation to obstruct the ostiomeatal unit and the air passages may imply a role in the development and recurrence of sinusitis, although such a causal relationship has never been documented.

Septal deviations may compromise key areas like the ostiomeatal unit, which can cause impaired drainage of the sinuses. This may be associated with a concha bullosa or a hypertrophied middle turbinate on the roomy side, which may compromise the ostiomeatal unit. The septum may sometimes be pneumatized. The middle turbinate may show a sharp bend laterally, instead of its smooth medial curvature. It is usually bilateral \& causes obstruction of the infundibulum. The uppermost portion of the uncinate process may sometimes be pneumatized, \& can cause obstruction of the infundibulum.

\section{Statistical Analysis}

Data was entered in Microsoft excel and analysis was done using SPSS version 20. Descriptive statistical analysis was done. Results on categorical measurements are presented as Percentages. Significance is assessed at $5 \%$ level of significance. $\mathrm{P}<0.01-$ statistically significant. Fisher's exact test/Chi square test was used.

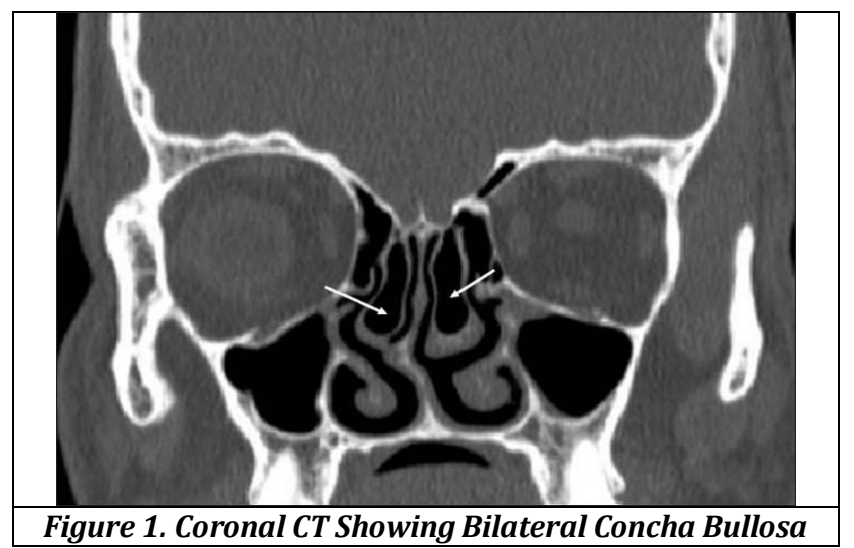

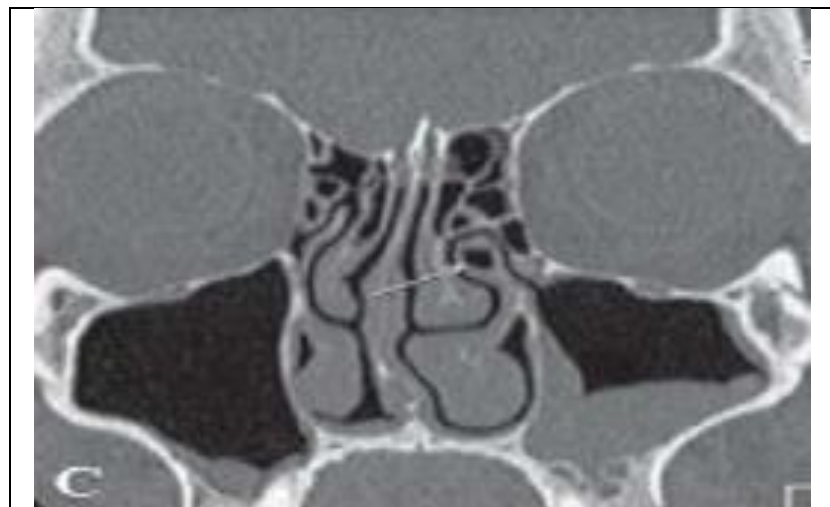

Figure 2. Coronal Image Showing Pneumatized Uncinate Process

Anterior ethmoid cells pneumatize the lacrimal bone \& the frontonasal process of the maxilla. A prominent agger nasi cell produces a distinct bulge anterior to anterior attachment of middle turbinate \& may even displace the anterior attachment of middle turbinate posterosuperiorly. Haller cells are formed by pneumatization of the roof of the maxillary sinus by anterior ethmoid cell. It is usually seen in the floor of the orbit \& can compromise the infundibulum. Posterior ethmoid cells may pneumatize the sphenoid bone posteriorly, giving rise to the Onodi cell. The lateral wall of this cell is closely related to the optic nerve \& the internal carotid artery.

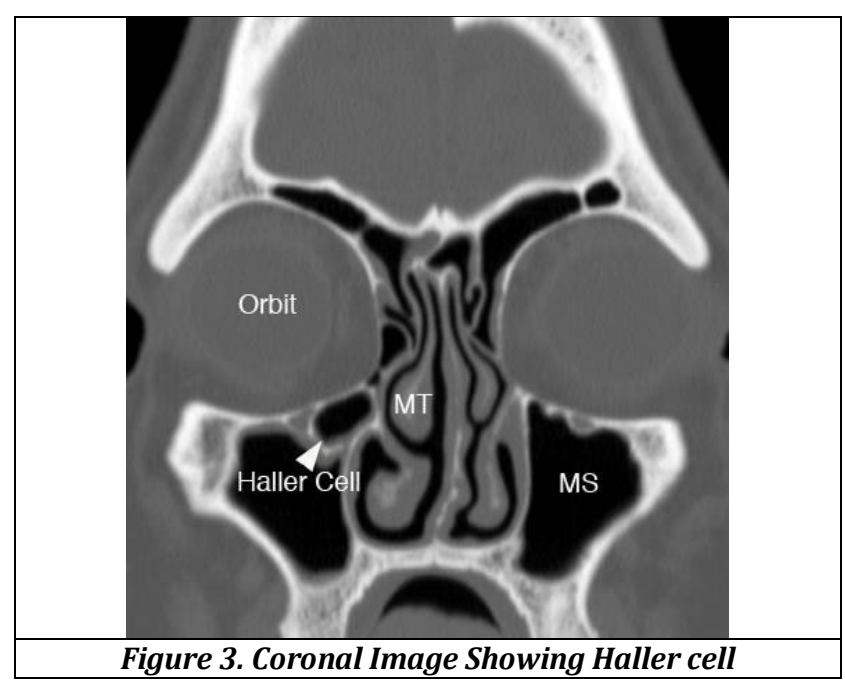

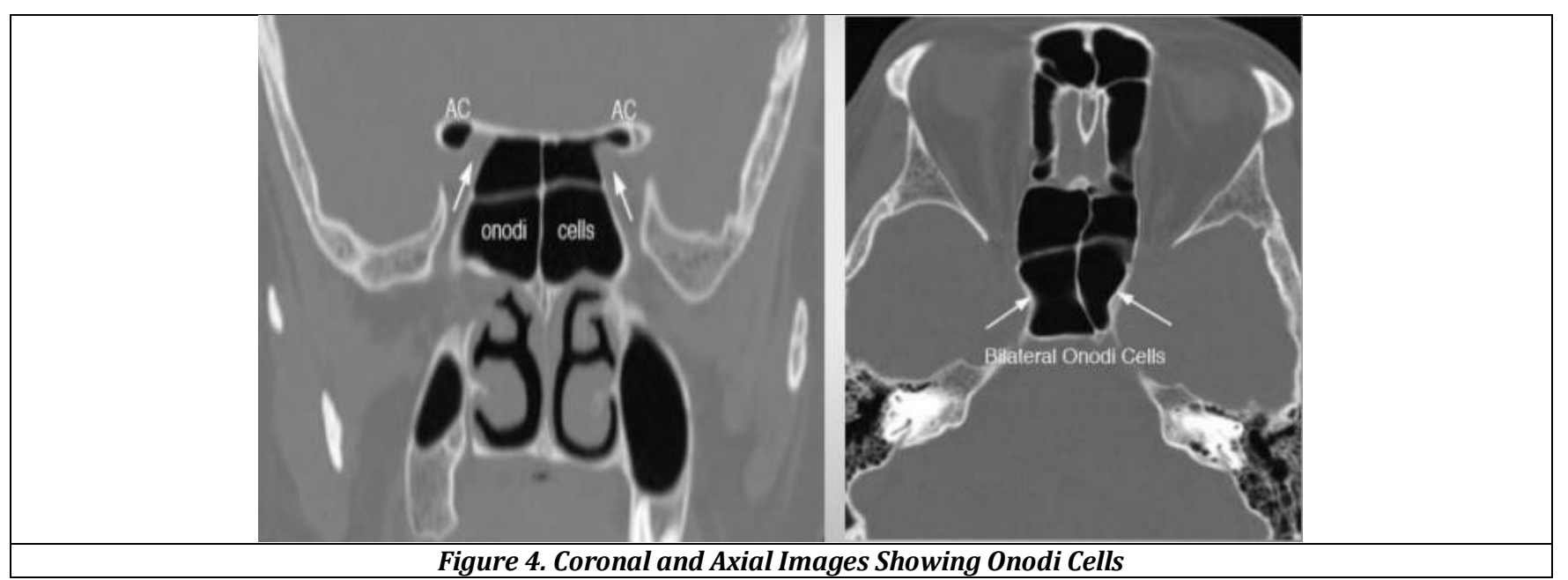




\section{RESULTS}

Of the 86 patients studied, 72 patients $(83.7 \%)$ had at least one anatomical variation. In this study, 63 patients $(73.25 \%)$ had DNS; $37.3 \%$ of patients had DNS to right, $32.5 \%$ had DNS to left and $3.5 \%$ had ' $\mathrm{S}$ ' shaped DNS. Of the 63 patients with DNS, 31 (50\%) were C shaped, 3 (3.2\%) were S shaped and $29(46.8 \%)$ were septal spurs. DNS was the commonest anatomical variation obtained; hence it was assessed separately in detail.

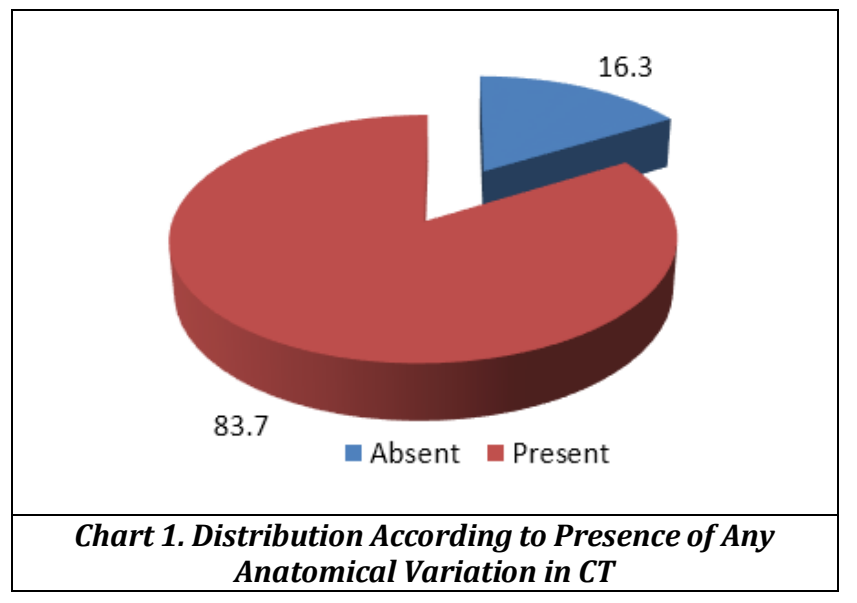

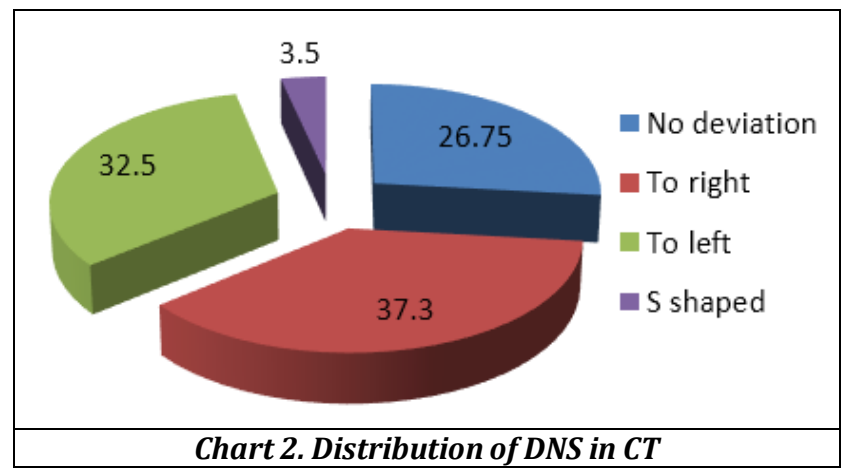

Among the anatomical variations studied, DNS was the most common variation found, followed by concha bullosa (37.2\%), onodi cell (12.8\%), agger nasi cell (8.14\%), haller cell and paradoxical middle turbinate $(3.5 \%$ each $)$, retroverted uncinate $(2.32 \%)$ and pneumatized uncinate process $(1.16 \%)$ in that order.

\begin{tabular}{|c|c|c|c|c|c|c|c|c|}
\hline \multirow{2}{*}{ Anatomical Variation } & \multicolumn{2}{|c|}{ Bilateral } & \multicolumn{2}{|c|}{ Right } & \multicolumn{2}{|r|}{ Left } & \multirow{2}{*}{$\begin{array}{l}\text { Total } \\
\text { Count }\end{array}$} & \multirow{2}{*}{ Percentage } \\
\hline & Count & Percentage & Count & Percentage & Count & Percentage & & \\
\hline Concha Bullosa & 12 & 13.9 & 11 & 12.8 & 9 & 10.46 & 32 & 37.2 \\
\hline Haller Cell & 2 & 2.32 & 1 & 1.16 & 0 & 0.0 & 3 & 3.5 \\
\hline Onodi Cell & 11 & 12.8 & 0 & 0.0 & 0 & 0.0 & 11 & 12.8 \\
\hline Agger Nasi Cell & 2 & 2.32 & 1 & 1.16 & 4 & 4.65 & 7 & 8.14 \\
\hline Paradoxical Middle Turbinate & 3 & 3.5 & 0 & 0.0 & 0 & 0.0 & 3 & 3.5 \\
\hline Pneumatised Uncinate Process & 0 & 0.0 & 0 & 0.0 & 1 & 1.16 & 1 & 1.16 \\
\hline Retroverted Uncinate & 0 & 0.0 & 1 & 1.16 & 1 & 1.16 & 2 & 2.32 \\
\hline Pneumatised Vomer & 0 & 0.0 & 0 & 0.0 & 0 & 0.0 & 0 & 0 \\
\hline \multicolumn{9}{|c|}{ Table 1. Distribution of Anatomical Variations Other Than DNS in CT } \\
\hline \multicolumn{9}{|c|}{ (p value $<0.01)$} \\
\hline
\end{tabular}

70 out of 86 patients $(81.4 \%)$ had bilateral chronic rhinosinusitis (CRS) while 16 patients $(18.6 \%)$ had unilateral disease, of which $10(11.6 \%)$ and $6(7 \%)$ patients had right sided and left sided disease respectively.

Among the 10 patients with right sided CRS, 7 patients had anatomical variation(s) on the right side, and 3 patients had bilateral anatomical variations. 5 out of 6 patients with left sided CRS had left sided anatomical variation (s) while 1 patient had bilateral anatomical variations.

Of the 70 patients with bilateral CRS, 39 patients (55.7\%) had bilateral anatomical variations, while $10 \%$ and $14.3 \%$ patients had right and left sided anatomical variations respectively. 14 patients (20\%) had no anatomical variation. As many of the patients had multiple variations in various combinations, individual assessment of each variation could not be done.

\begin{tabular}{|c|c|c|}
\hline Anatomical Variation (s) & Count & Percentage \\
\hline Right Sided & 7 & 10.0 \\
\hline Left Sided & 10 & 14.3 \\
\hline Bilateral & 39 & 55.7 \\
\hline No Variation & 14 & 20.0 \\
\hline Total & 70 & 100 \\
\hline $\begin{array}{c}\text { Table 3. Distribution of Laterality of Anatomical } \\
\text { Variations in Patients with Bilateral CRS }\end{array}$ \\
\hline
\end{tabular}

$35(40.7 \%)$ of the total 86 patients had polyp in CT scan. No statistical association was found between nasal allergy and nasal polyposis.

The maximum score based on Lund- MacKay scoring was 22 , the minimum score was 6 , and the mean was 12.6 with a standard deviation of 3.9 .

\begin{tabular}{|c|c|}
\hline Mean & 12.6 \\
\hline S.D. & 3.9 \\
\hline Median & 12.5 \\
\hline Mode & 9.0 \\
\hline Minimum & 6.0 \\
\hline Maximum & 22.0 \\
\hline Table 4. Lund- MacKay CT Score \\
\hline
\end{tabular}

\section{DISCUSSION}

Management of chronic rhinosinusitis not responding to medicines has evolved over the recent years. ESS, which aims at removal of disease from the sinuses and improving the sinus drainage and ventilation, requires a thorough knowledge about the anatomy of the nose and paranasal sinuses and also the vital structures in the vicinity, which shows wide variations from person to person. 
Computed tomography is the investigation of choice for the evaluation of patients with CRS. Although CRS is a clinically diagnosable disease, CT is an important aspect of pre-operative planning of patients. CT provides a good perspective of sinonasal anatomy and pathology of both bone and soft tissue components. In this study, a humble attempt was made to identify the various sinonasal anatomical variations and their prevalence in diagnosed cases of chronic rhinosinusitis, who have failed to respond to medical management and were planned for endoscopic sinus surgery at the Department of Otorhinolaryngology, Government Medical College, Thiruvananthapuram, during the period, March 2016 to August 2017. This study included 86 patients. After a detailed history taking and general examination, the CT of the patients were studied for anatomical variations and results analysed. The results were then compared with that of similar studies conducted elsewhere previously.

Although sinonasal anatomical variations as a cause of sinusitis is debated, it is widely accepted that any obstruction at the ostiomeatal complex region can lead to a vicious cycle of mucosal congestion which decreases air flow, and can predispose to further obstruction. DNS can cause nasal obstruction and can affect the ventilation of the paranasal sinuses on the side to which the septum is deviated. In our study, 63 out of the 86 patients (73.25\%) had DNS, which is almost similar to as reported by Perez- Pinas et al, ${ }^{2}$ and Suri $\mathrm{N}$ et al, ${ }^{3}$ which are $80 \%$ and $75 \%$ respectively.

Concha bullosa has been implicated as a possible aetiological factor in the pathogenesis of recurrent or chronic rhinosinusitis. It is due to its unfavourable impact on the ventilation and mucociliary clearance of the OMC region. In our study $37.2 \%$ patients had concha bullosa, which is almost comparable to that reported by Suri $\mathrm{N}$ et $\mathrm{al}^{3}$ (41.6\%), and Pradeep Kumar et $\mathrm{al}^{4}$ (43\%). But it is much less when compared to that reported by Perez- Pinas et $\mathrm{al}^{2}$ and Scribano et al, 5 which were $73 \%$ and $67 \%$ respectively.

A paradoxically curved middle turbinate can impinge on the middle meatus, and thus predispose to chronic rhinosinusitis. It may also alter the nasal airflow dynamics. 3 (3.5\%) out of the 86 patients had paradoxical middle turbinate, which is reported to be $16 \%$ by Gouripur $\mathrm{K}$ et al, 6 $12 \%$ by Asruddin et al, 7 and $8.3 \%$ by Suri $\mathrm{N}$ et al. ${ }^{3}$

$12.8 \%$ of the patients included in this study had Onodi cells, which is on the higher side as compared to Gouripur $\mathrm{K}$ et $\mathrm{al}^{6}(6 \%)$ and Suri $\mathrm{N}$ et $\mathrm{al}^{3}(4.1 \%)$. The Onodi cells lie in close proximity to the optic nerve and carotid canal, which emphasizes the importance of considering this anatomical variation prior to any surgical intervention in the vicinity.

The presence of Haller cells can increase the risk of orbital injury during ethmoidectomy. Haller cells can predispose to maxillary sinusitis. The percentage of patients having Haller cells in our study was $3.5 \%$, while it was $2 \%$ as reported by Aramani A et al ${ }^{8}$ and $1 \%$ as reported by Liu X et al. ${ }^{9}$ This is much lower when compared to that reported by Dua et $\mathrm{al}^{10}(16 \%)$ and Lloyd et al ${ }^{11}(15 \%)$.

Agger nasi cells lie just anterior to the anterosuperior attachment of the middle turbinate and may invade the lacrimal bone or the ascending process of the maxilla. 8.14\% (7) patients in our study had agger nasi cells, similar to that reported by Liu X et al ${ }^{9}$ (7.8\%) and Lloyd et al ${ }^{11}$ (8.5\%), but much less as compared to that reported by Bolger et al ${ }^{12}$ (98.5\%) and Maru et $\mathrm{al}^{13}$ (88.5\%).

Pneumatised uncinate process was seen in 1 patient $(1.16 \%)$ while retroverted uncinate was present in 2 patients $(2.32 \%)$ in our study while it was reported to be $2 \%$ and $16 \%$ respectively, by Gouripur K et al. ${ }^{6}$ Pneumatised uncinate process was reported in as high as $21 \%$ patients by Wani et al.14 None of the patients in our study had pneumatised vomer but it was reported to be $1.6 \%$ by Suri $\mathrm{N}$ et al, ${ }^{3}$ and $2.7 \%$ by Dakshina Murthy et al.

Out of the 86 patients with CRS studied, 72 patients $(83.7 \%)$ had at least one sinonasal anatomical variation, while the rest 14 patients (16.3\%) didn't have any.

70 out of 86 patients ( $81.4 \%$ ) had bilateral disease while 16 patients had unilateral disease, of which 10 (11.6\%) patients and $6(7 \%)$ patients had right sided and left sided disease respectively. All the patients with unilateral disease had single or multiple anatomical variations affecting the same side, which suggests the role of anatomical variations in the etiology of chronic rhinosinusitis. $90 \%$ of the patients with right sided disease had DNS to right, with associated bilateral concha bullosa in $20 \%$ and left agger nasi cell in $10 \%$. The rest $10 \%$ had right sided concha bullosa alone. All the patients with left sided disease had DNS to left, with associated left concha bullosa, left agger nasi cell and bilateral onodi cells in $16.6 \%$ each. By using chi square test, a statistically significant correlation was derived between the side of disease (CRS) and the side where anatomical variation was found ( $p$ value <0.01). This is similar to the study conducted by Deosthale et $\mathrm{al}^{15}$ in which a statistically significant correlation was found between right septal deviation and right maxillary sinusitis. Similarly, a study conducted by Fadda GL et al,16 a statistically significant correlation was found between left septal deviation and left maxillary sinusitis.

Of the 70 patients with bilateral CRS, 39 patients (55.7\%) had bilateral anatomical variations, while $10 \%$ patients had only right sided anatomical variations and $14.3 \%$ had only left sided anatomical variations. 14 patients (20\%) had no anatomical variation. As many patients had multiple variations, each variation could not be studied separately.

The CT scores were done using Lund-MacKay scoring where the maximum score was 22, minimum score was 6 and the mean total score was 12.6. In a study conducted by Pokheral et al, ${ }^{17}$ an average total score of 11.3 was obtained, which is almost similar to that of our study.

A significant proportion of patients (40.7\%) had associated nasal polyps on CT. $46.5 \%$ patients had associated nasal allergy. No statistically significant association could be found between nasal allergy and nasal polyposis ( $p$ value0.902).

\section{CONCLUSION}

1. The prevalence of sinonasal anatomical variations in CRS patients in our study was $83.7 \%$ (72 patients).

2. Deviated nasal septum is the most common sinonasal anatomical variation studied $(73.25 \%)$, followed by concha bullosa (37.2\%).

3. All the patients with unilateral disease had single or multiple anatomical variations affecting the same side, 
which suggests the role of anatomical variations in the aetiology of chronic rhinosinusitis. By using chi square test, a statistically significant correlation was derived between the side of disease (CRS) and the side where anatomical variation was present in patients with unilateral disease ( $\mathrm{p}$ value $<0.01$ ).

4. Bilateral anatomical variations were more common than unilateral anatomical variations.

5. Bilateral CRS was more common than unilateral CRS.

\section{REFERENCES}

[1] Gleeson MJ, Jones NS, Clarke R, et al. Scott-Brown's Otorhinolaryngology: head and neck surgery. $7^{\text {th }}$ edn. CRC Press 2008.

[2] Perez-Pinas, Sabate J, Carmona A, et al. Anatomical variations in the human paranasal sinus region studied by CT. J Anat 2000;197(Pt 2):221-7.

[3] Suri N, Janardan T, Parmar H. Correlation of anatomical variations of paranasal sinuses and chronic rhinosinusitis. Int Arch Integ Med 2016;3(12):84-8.

[4] Kumar P, Rakesh BS, Prasad R. Anatomical variations of sinonasal region, a coronal CT scan study. Int J Contemporary Med Res 2016;3(9):2601-4.

[5] Scribano E, Ascenti G, Loria G, et al. The role of the ostiomeatal unit anatomic variations in inflammatory disease of the maxillary sinuses. Eur J Radiol 1997;24(3):172-4.

[6] Gouripur K, UdayaKumar M, Janagond A, et al. Incidence of sinonasal anatomical variations associated with chronic sinusitis by CT scan in Karaikal, South India. Int J Otorhinolaryngol \& Head Neck Surg 2017;3(3):576-80.

[7] Asruddin, Yadav SPS, Yadav RK, et al. Low dose CT in chronic sinusitis. Indian J Otolaryngol Head \& Neck Surg 1999;52(1):17-22.
[8] Aramani A, Karadi RN, Kumar S. A study of anatomical variations of osteomeatal complex in chronic rhinosinusitis patients - CT findings. J Clin Diagn Res 2014;8(10):KC01-4.

[9] Liu X, Han D, Zhou B. Relationship between anatomic variations of nasal sinus and chronic sinusitis. Zhonghua Er Bi Yan Hou Ke Za Zhi. 1998;33(3):14952. (In Chinese).

[10] Dua K, Chopra H, Khurana AS, et al. CT scan variations in chronic sinusitis. Ind J Radiol Imag 2005; 15:(3):315-20.

[11] Llyod GA. CT scan of the paranasal sinuses:study of a control series in relation to endoscopic sinus surgery. J Laryngo Rhino Otol 1990;104(6):477-81.

[12] Bolger WE, Butzin CA, Parsons DS. Paranasal sinus bony anatomic variations and mucosal abnormalities: CT analysis for endoscopic sinus surgery. Laryngoscope 1991;101(1 Pt 1):56-64.

[13] Maru YK, Gupta Y. Concha bullosa: frequency and appearances on sinonasal CT. Indian J Otolaryngol Head \& Neck Surg 1999;52(1):40-4.

[14] Wani AA, Kanotra S, Lateef M, et al. CT scan evaluation of the anatomical variations of the ostiomeatal complex. Indian J Otolangol Head Neck Surg 2009:61(3):163-8.

[15] Deosthale NV, Khadakkar SP, Singh B, et al. Anatomical variations of nose and paranasal sinuses in chronic rhinosinusitis. People's Journal of Scientific Research 2014;7(2):1-7.

[16] Fadda GL, Rosso S, Aversa S, et al. Multiparametric statistical correlations between paranasal sinus anatomic variations and chronic rhinosinusitis. Acta Otorhinolaryngol Ital 2012;32(4):244-51.

[17] Pokheral M, Karki S, Shrestha BL, et al. Correlations between symptoms, nasal endoscopy, computed tomography and surgical findings in patients with chronic rhinosinusitis. Kathmandu Univ Med J (KUMJ) 2013;11(43):201-5. 